\title{
Identifikasi Struktur Tanah Bawah Permukaan dan Kedalaman Akuifer Daerah Tempat Pemrosesan Akhir (TPA) Manggar Menggunakan Metode Resistivitas Konfigurasi Schlumberger
}

\author{
Mohammad Muntaha, ${ }^{1, *}$ Jakaria Aspan Latifah², Febrian Dedi Sastrawan² \\ Departemen Teknik Infrastuktur Sipil, Institut Teknologi Sepuluh Nopember, Surabaya ${ }^{1}$ \\ Jurusan Sains, Teknologi Pangan dan Kemaritiman, Institut Teknologi Kalimantan, Balikpapapan² \\ Koresponden*, Email: mohammadmuntaha@yahoo.com
}

\begin{tabular}{lll}
\hline & Info Artikel & Abstract \\
\hline Diajukan & 20 Juli 2018 & Water for daily is big problem for people living around of Manggar Final Processing Place \\
Diperbaiki & (T) Agustus 2018 & (TPA) - Balikpapan. This study aims to identify the depth of aquifer and subsurface structures \\
Disetujui & around the Manggar TPA area using the geo-electric resistivity method configuration schlum- \\
& berger. The data obtained in the acquisition process is used to calculate the apparent resistivity \\
value at each measurement point and analyzed quantitatively and qualitatively. Then proceed & with the inversion process using IP2 Win program so that obtained resistivity value and layer \\
& thickness at each point of measurement. The result of measurement showed that subsurface \\
& structures at each point of measurement have a similarity, at the top layer is a top soil layer \\
& with the impermeable layer. Next layer is a layer of clay layer that a permeable layer, the last \\
& is a sandstone layer that has a function as a layer of ground water aquifers. The depth of \\
& groundwater aquifers from the subsurface at each point of measurement varies with a shallow \\
& aquifer at the second measurement point $1,15-7,68$ meter and the deepest aquifers at the third \\
measurement point 41,2-61,7 meter. The range of aquifer resistivity values at each \\
measurement point varies from $7,33 \Omega m-27,4 \Omega m$.
\end{tabular}

\begin{abstract}
Abstrak
Air menjadi persoalan bagi warga sekitar daerah Tempat Pemrosesan Akhir (TPA) Manggar Balikpapan. Penelitian ini bertujuan untuk mengidentifikasi kedalaman akuifer dan struktur bawah permukaan sekitar daerah TPA Manggar dengan menggunakan metode geolistrik konfigurasi Schlumberger. Data yang diperoleh pada proses akusisi digunakan untuk menghitung nilai resistivitas semu pada setiap titik pengukuran dan dianalisisi secara kuantitatif dan kualitatif. Proses dilanjutkan dengan inversi menggunakan program IP2 Win sehingga didapatkan nilai resistivitas dan ketebalan lapisan pada setiap titik pengukuran. Hasil pengukuran terlihat bahwa struktur bawah permukaan pada setiap titik pengukuran memiliki kesamaan, yaitu pada lapisan teratas merupakan lapisan top soil dengan lapisan kedap air (impermeable). Dibawahnya merupakan lapisan lempung yang lolos air (permeable), selanjutnya adalah lapisan pasir yang memiliki fungsi sebagai lapisan akuifer air tanah. Kedalaman lapisan akuifer air tanah menunjukkan hasil yang berbeda-beda, akuifer terdangkal pada titik pengukuran kedua yaitu 1,15-7,68 meter dan akuifer terdalam pada titik pengukuran ketiga yaitu 41,2-61,7 meter. Rentang nilai resistivitas akuifer pada tiap titik pengukuran bervariasi berkisar $7,33 \Omega \mathrm{m}-27,4 \Omega \mathrm{m}$.
\end{abstract} Akuifer, Geolistrik, Resistivitas, Schlumberger

\section{Pendahuluan}

Air merupakan kebutuhan dasar bagi manusia. Balikpapan merupakan salah satu kota di Kalimantan Timur, Indonesia yang memiliki penduduk sebanyak 735.850 jiwa, dimana jumlah tersebut merupakan 22\% dari jumlah keseluruhan penduduk Kalimantan Timur. Setiap tahunnya kota Balikpapan mengalami peningkatan jumlah penduduk, bisa dari kelahiran ataupun perantau yang semakin banyak mencari kerja.

Tempat Pemrosesan Akhir (TPA) Manggar berlokasi di kelurahan Manggar yang terletak di kecamatan Balikpapan Timur yang merupakan kawasan pantai. Daerah tersebut memiliki topografi yang berbukit-bukit [1], menyebabkan
PDAM tidak bisa mendistribusikan air secara merata ke warga sekitar yang tinggal pada daerah tersebut. Banyak dari warga yang mencari alternatif lain dalam memenuhi kebutuhan akan air untuk kesehariannya, salah satunya dengan membuat sumur galian. Air pada sumur galian yang didapatkan umumnya pada kedalaman \pm 5 meter, memiliki warna keruh dan tidak dapat langsung digunakan. Air sumur galian yang diperoleh merupakan air tanah yang dekat dengan permukaan atau akuifer dangkal yang masih bercampur dengan material permukaan. Untuk itu diperlukan cara untuk menemukan air tanah dalam yang memiliki kualitas yang lebih baik dari air tanah dangkal. Salah satu metode yang dapat digunakan adalah metode resistivitas. 
Resistivitas atau tahanan jenis dapat ditentukan dengan menggunakan hukum Ohm. Hukum Ohm secara umum menyatakan bahwa besar arus listrik (I) yang mengalir melalui sebuah penghantar atau konduktor akan berbanding lurus dengan beda potensial/tegangan (V) yang diterapkan kepadanya dan berbanding terbalik dengan hambatannya (R). Secara matematis dituliskan sebagai berikut [2]:

$$
\mathrm{I}=\frac{\mathrm{V}}{\mathrm{R}} \text {. }
$$

Metode geofisika yang digunakan pada pemetaan struktur tanah bawah permukaan dan akuifer air tanah adalah metode geolistrik. Metode geolistrik merupakan metode geofisika aktif yang digunakan untuk mengetahui struktur lapisan tanah bawah permukaan berdasarkan sifat kelistrikannya. Metode resistivitas memanfaatkan perbedaan nilai resistivitas batuan/tanah bawah permukaan untuk mendeteksi struktur geologi atau formasi batuan bawah permukaan. Pada prinsipnya, metode geolistrik bekerja dengan dengan cara mengalirkan arus listrik ke dalam tanah. Injeksi arus listrik ini melalui 2 buah elektroda arus dengan simbol A dan B (C1 dan C2) yang ditanamkan ke dalam tanah dengan jarak tertentu. Semakin panjang jarak elektroda $\mathrm{AB}$ akan menyebabkan aliran arus listrik bisa menembus lapisan batuan lebih dalam. Gambaran umum metode geolistrik seperti terlihat pada Gambar 1.

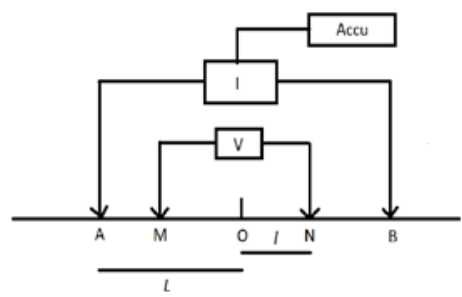

Gambar 1. Bentuk susunan elektroda metode geolistrik tahanan jenis.

Pada eksplorasi geolistrik, untuk mengukur resitivitas dilapangan digunakan persamaan berikut:

$\rho_{\mathrm{a}}=\frac{\Delta \mathrm{V}}{\mathrm{I}} \mathrm{K}$

dimana bumi diasumsikan mempunyai sifat homogen isotropis [3]. Dengan asumsi ini, resistivitas yang terukur merupakan resistivitas sebenarnya dan tidak tergantung atas spasi elektroda. Pada kenyataannya, bumi terdiri dari lapisanlapisan dengan nilai resistivitas yang berbeda-beda, sehingga potensial yang terukur merupakan pengaruh dari lapisanlapisan tersebut (bumi tidak homogen isotropis). Sehingga nilai resistivitas yang di didapatkan di daerah pengukuran pada medium yang tidak homogen bukanlah nilai resistivitas sebenarnya dikarenakan nilai resistivitas yang didapatkan merupakan nilai resistivitas gabungan dari seluruh lapisan yang ada. Resistivitas inilah yang disebut sebagai resistivitas semu (apparent resistivity).

Terdapat beberapa konfigurasi elektroda dan faktor geometri yang dikenal dalam metode geolistrik tahanan jenis seperti Wenner, Schlumberger, dan Dipole-dipole [3]. Konfigurasi yang umumnya digunakan untuk keperluan estimasi kedalaman lapisan air tanah (akuifer) yaitu konfigurasi Schlumberger. Konfigurasi Schlumberger didasarkan oleh pengukuran yang memiliki keberlanjutan pengukuran dalam satu penampang dan hasilnya disebut sebagai penampang semu (pseudosection). Pengukuran ini dilakukan dengan membuat variasi posisi elektroda arus (AB) dan elektroda potensial (MN). Gambar 2 merupakan susunan elektroda konfigurasi Schlumberger [4].

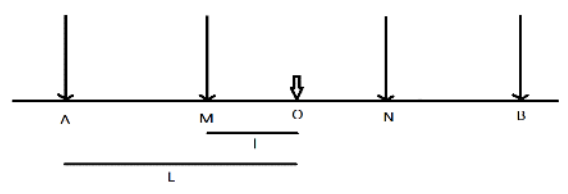

Gambar 2. Konfigurasi Geolistrik Metode Schlumberger

Dalam konfigurasi Sclumberger ini dapat dihitung nilai resistivitas semu rumusan faktor geometri dapat dituliskan $\rho_{\mathrm{a}}=\frac{\pi}{2 \mathrm{l}}\left(\mathrm{L}^{2}-\mathrm{l}^{2}\right)\left(\frac{\Delta \mathrm{V}}{\mathrm{I}}\right)$

Hasil yang diharapkan adalah data distribusi resistivitas dari setiap titik pengukuran yang digunakan untuk membuat model penampang lapisan resistivitas tanah bawah permukaan dari setiap titik pengukuran. Dari model penampang lapisan resistivitas yang diperoleh diharapkan dapat menggambarkan struktur lapisan tanah bawah permukaan dari setiap titik pengukuran sehingga dapat diperkirakan kedalaman dari lapisan akuifer air tanah di setiap titik pengukuran.

\section{Metode}

Pengambilan data lapangan dilakukan selama dua hari yaitu pada tanggal 20 Januari hingga 21 Januari 2018, pada hari sabtu dan minggu berlokasi di sekitar daerah Tempat Pemrosesan Akhir (TPA) Manggar Kota Balikpapan. Apabila pada hari pengukuran terjadi hujan, maka pengukuran akan dilakukan keesokan harinya. Hal ini bertujuan agar nilai beda potensial dan arus yang didapatkan tanpa dipengaruhi oleh air hujan.

Pada penelitian diambil 5 titik lintasan untuk pengukuran resistivitas tanah. Pengukuran ini dilakukan dengan cara meletakkan titik titik elektroda dengan beda jarak satu sama lain yang sama. Elektroda yang bersebelahan akan berjarak sama $(\mathrm{AM}=\mathrm{MN}=\mathrm{NB}=\mathrm{a})$. Konfigurasi ini memiliki kelebihan 
dalam ketelitian pembacaan karena memiliki nilai eksentrisitas yang tidak terlalu besar atau bernilai sebesar 1/3 [5].

Data-data yang telah didapatkan dianalisis dan diolah terlebih dahulu sehingga didapatkan interpretasi data yang baik dan dapat dipertanggung jawabkan. Akuisi data pada setiap titik pengukuran diulangan sebanyak tiga (3) kali, hal ini bertujuan untuk mendapatkan data yang baik dan maksimal. Dari data tersebut maka dapat dihitung besar nilai resistivitas semu pada setiap titik pengukuran dengan dianalisis terlebih dahulu, kemudian diolah menggunakan program IP2 Win agar diperoleh permodelan struktur bawah permukaan dari setiap titik pengukuran dan juga interpretasi datanya. Data yang diperoleh dari pengolahan dengan program IP2 Win berupa perlapisan batuan berdasarkan nilai resistivitasnya, ketebalan lapisan, kedalaman lapisan dan besar kesalahan (error) yang dihasilkan.

\section{Hasil dan Pembahasan}

Hasil akuisisi data berupa nilai beda potensial $(\Delta \mathrm{V})$, arus listrik (I) yang dicatat ke dalam tabel nilai berkonfigurasi Schlumberger, termasuk nilai faktor geometri (K). Dari data tersebut akan didapatkan nilai resisitivitas semu $\left(\rho_{a}\right)$ pada setiap titik pengukuran. Terdapat dua analisis data pada penelitian ini, yaitu analisis secara kuantitatif dan kualitatif. Setelah didapatkan analisis data, dilanjutkan dengan interpretasi data yang bertujuan menjelaskan dan menggambarkan struktur bawah permukaan tanah di setiap titik pengukuran. Interpretasi data pada penelitian ini berupa penampang lapisan satu (1) dimensi pada setiap titik pengukuran berdasarkan nilai resistivitas, ketebalan, dan kedalaman serta penampang lapisan dua (2) dimensi yang didapatkan dari korelasi pada beberapa titik pengukuran. Hasil pengukuran terlihat pada Gambar 3-7.

Hasil penampang satu (1) dimensi yang diperoleh pada titik pengukuran pertama menunjukkan terdapat potensi akuifer air tanah dengan perkiraan lapisan batu lempung pasiran berada di kedalaman 11,9 meter - 20,8 meter dari permukaan tanah. Adapun nilai resistivitas tertinggi pada titik pengukuran diperkirakan sebagai lapisan batuan batu bara yang terletak pada kedalaman 1 - 5 meter.

Pada titik pengukuran kedua, diperkirakan terdapat dua jenis akuifer yaitu akuifer dangkal dan akuifer dalam.

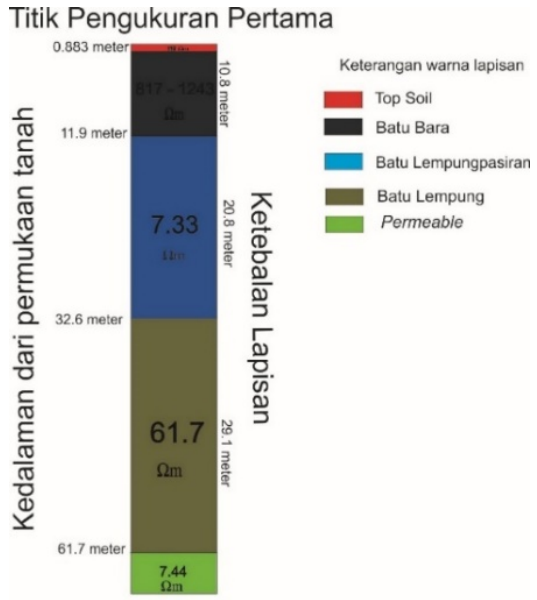

Gambar 3. Penampang lapisan satu (1) dimensi pada titik pengukuran pertama

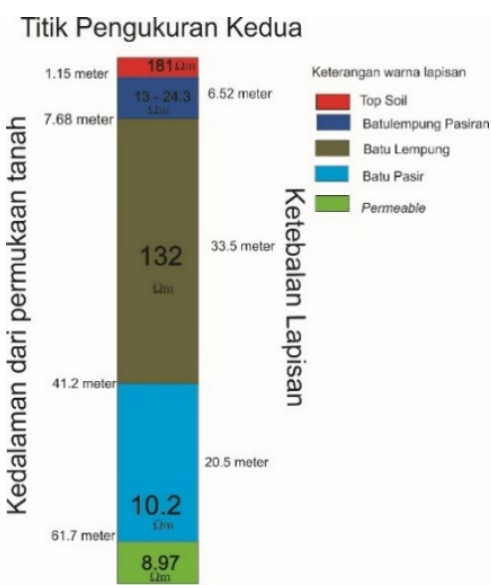

Gambar 4. Penampang lapisan satu (1) dimensi pada titik pengukuran kedua

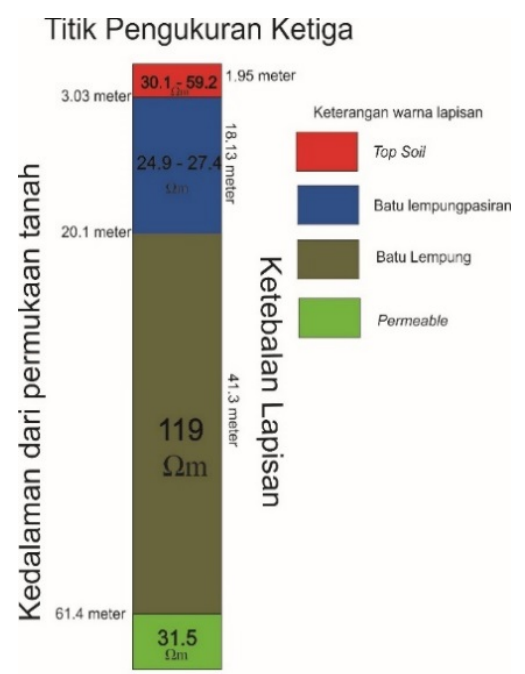

Gambar 5. Penampang lapisan satu (1) dimensi pada titik pengukuran ketiga 


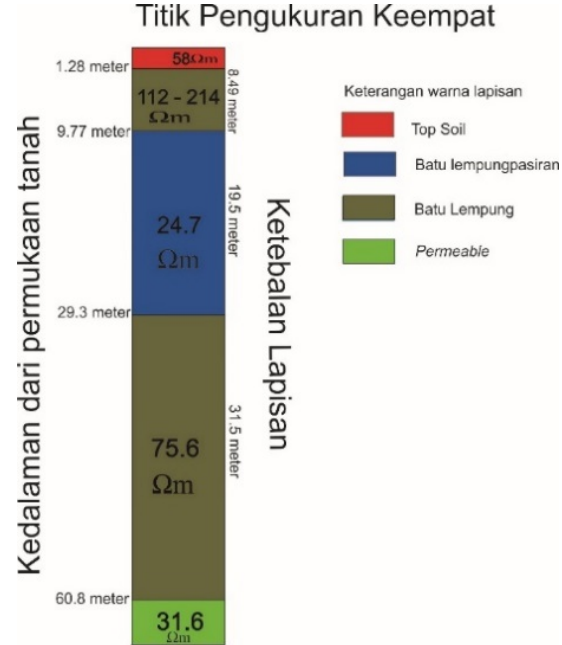

Gambar 6. Penampang lapisan satu (1) dimensi pada titik pengukuran keempat

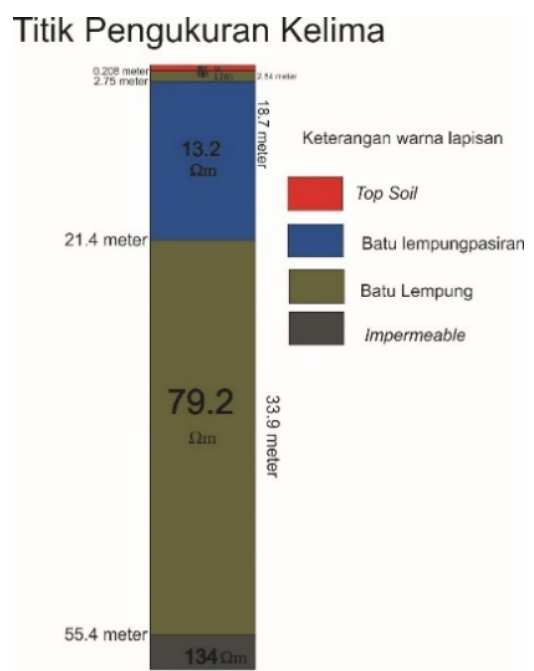

Gambar 7. Penampang lapisan satu (1) dimensi pada titik pengukuran kelima

Akuifer dangkal yang diperoleh diperkirakan berbentuk lensa, lapisan tersusun dari batuan lempung pasiran yang terletak pada kedalaman 1,15 meter hingga 7,68 meter dibawah permukaan tanah dengan ketebalan 6,52 meter. Adapun akuifer dalam terletak pada kedalaman 41,2 meter hingga 61,7 meter dibawah permukaan tanah dengan ketebalan lapisan 20,5 meter, diperkirakan lapisan tersebut tersusun dari batu pasir yang memiliki ukuran butir yang besar (batuan berporus) dan pori-porinya tersebut saling terhubung satu sama lain. Ketebalan akuifer dalam diperkirakan masih dapat bertambah dikarenakan lapisan dibawahnya bersifat permeable sehingga air tanah masih dapat meresap ke lapisan bawahnya.

Pada titik pengukuran ketiga didapatkan potensi akuifer pada kedalaman 3,03 meter hingga 20,1 meter dari permukaan tanah dengan ketebalan 18,13 meter. Lapisan akuifer ini termasuk akuifer dangkal karena dekat dengan permukaan dan diperkirakan tersusun dari batuan lempung pasiran serta merupakan akuifer bebas dikarenakan pada bagian atas memiliki nilai resistivitas yang rendah sehingga dapat bersifat meloloskan air (permeable).

Hasil penampang yang diperoleh pada titik pengukuran keempat menunjukkan bahwa titik pengukuran keempat memiliki potensi akuifer air tanah yaitu pada kedalaman 9,77 meter hingga 29,3 meter dengan ketebalan 19,5 meter. Jenis akuifer pada titik pengukuran ini adalah akuifer tertekan karena berada diantara dua lapisan yang bersifat kedap air.

Pengukuran terakhir, pada titik pengukuran kelima didapatkan potensi akuifer kedalaman 2,75 meter hingga 21,4 meter dibawah permukaan tanah dengan ketebalan 18,7 meter, diperkirakan tersusun dari lapisan batu lempung pasiran, lapisan ini merupakan akuifer tertekan.

Setelah didapatkan interpretasi penampang lapisan satu (1) dimensi berdasarkan nilai resistivitasnya pada setiap titik pengukuran, dilakukan korelasi penampang pada titik-titik tertentu pada daerah penelitian. Pada penelitian ini terdapat dua (2) penampang korelasi, yaitu pada titik 1-4-2 dan titik 3-5. Sebagaimana terlihat pada Gambar 8.

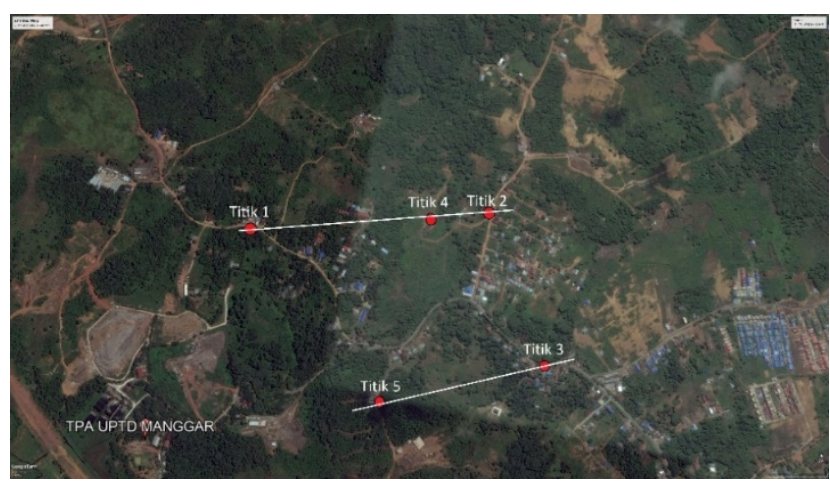

Gambar 8. Titik-titik korelasi pada daerah penelitian

Hasil penggambaran korelasi penampang pada lintasan 14-2 sebagaimana terlihat pada Gambar 9, sedangkan pada lintasan 3-5 terlihat pada Gambar 10.

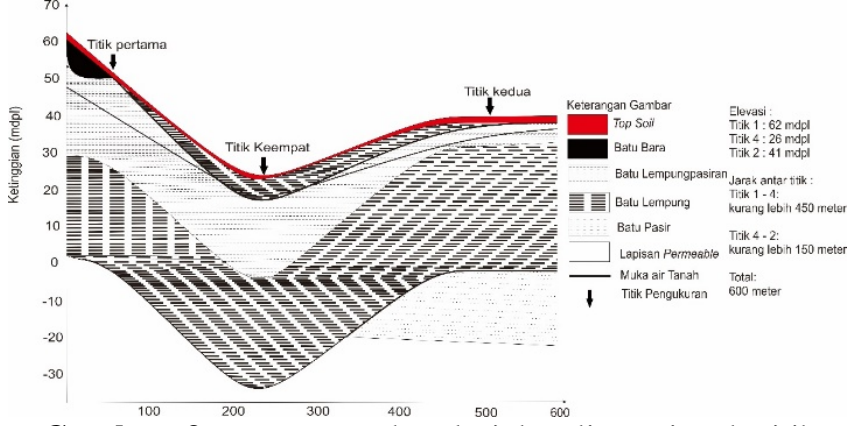

Gambar 9. Penampang korelasi dua dimensi pada titik pengukuran 1-4-2 
Berdasarkan hasil korelasi Gambar 9, terlihat bahwa lapis tanah bawah permukaan daerah sekitar TPA Manggar terdiri atas beberapa jenis tanah, lapis atas berupa top soil dengan kedalaman sekitar 1 meter, dibawahnya terdapat lapis batu bara muda dengan kedalaman 3-5 meter. Lapis di bawahnya adalah lempung dan lempung berpasir dengan ketebalan sekitar 20 meter. Wilayah ini adalah yang berpotensi sebagai akuifer.

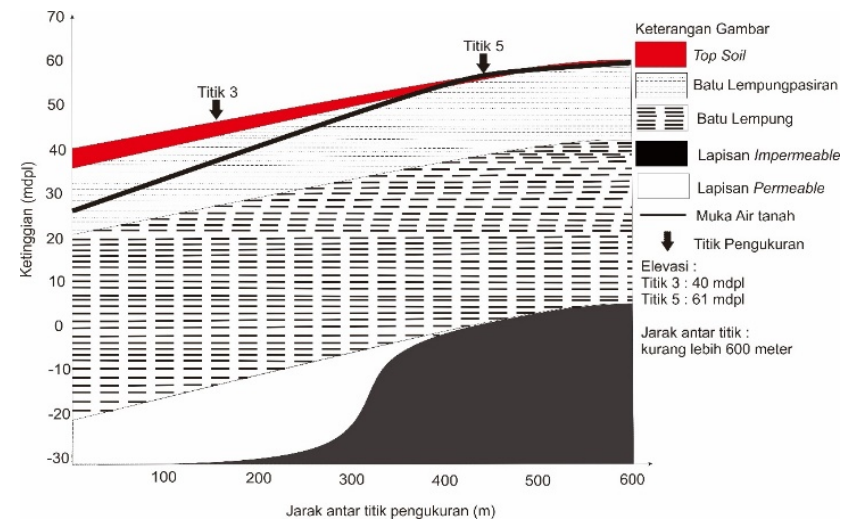

Gambar 10. Penampang korelasi dua dimensi pada titik pengukuran 3-5

Hasil korelasi titik pengukuran pada Gambar 10 menunjukkan bahwa lapis tanah bawah permukaan daerah sekitar TPA Manggar terdiri atas beberapa jenis tanah, lapis atas berupa top soil dengan kedalaman sekitar 1 sampai 2 meter, dibawahnya lapis Lempung berpasir dengan kedalaman 15-20 meter. Lapis di bawahnya adalah tanah lempung dengan ketebalan sekitar 20 meter. Pada wilayah ini adalah potensi akuifer sudah terlihat pada kedalaman 4 sampai 5 meter di bawah permukaan.

\section{Simpulan}

Berdasarkan hasil penelitian resistivitas daerah sekitar Tempat Pemrosesan Akhir (TPA) Manggar dengan menggunakan metode Geolistrik Sclumberger, maka dapat disimpulkan sebagai berikut:

1. Penelitian yang telah dilakukan memperoleh struktur bawah permukaan dan estimasi kedalaman lapisan akuifer air tanah pada setiap titik pengukuran dengan menggunakan distribusi nilai resistivitasnya.

2. Didapatkan model penampang satu dimensi dari setiap titik pengukuran dan model dua dimensi berdasarkan korelasi dari beberapa titik pengukuran telah dibuat dengan memperhatikan informasi geologi dalam pembuatannya.
3. Lapis bawah tanah permukaan secara umum adalah top soil, lapis batu bara muda, lempung berpasir dan lempung keras.

4. Kedalaman akuifer air tanah pada tiap titik pengukuran bervariasi dengan akuifer terdangkal pada titik pengukuran kedua yaitu 1,15-7,68 meter dari permukaan tanah dengan ketebalan 19.5 meter. Akuifer terdalam pada titik pengukuran kedua yaitu 41,2-61,7 meter dari permukaan tanah dengan ketebalan 20.5 meter. Kedua lapisan akuifer air tanah diperkirakan tersusun dari lempung berpasir. Nilai Resistivitas pada lapisan akuifer air tanah pada setiap titik pengukuran memiliki rentang nilai 7,33-24,7 $\Omega \mathrm{m}$.

\section{Daftar Pustaka}

[1] M. Mahyuzar., (2009). Administrasi, Transportasi, dan Pusat Perdagangan: SDA dan Sosial Budaya Kota Balikpapan, Provinsi Kalimantan Timur. Semarang, Indonesia.

[2] Halliday, Resnick. 1984. Fisika Jilid 1(Terjemahan). Jakarta: Penerbit Erlangga.

[3] Loke, M.H., (2000), Electrical Imaging Surveys For Environmental and Engineering Studies, A practical guide to 2-D and 3-D surveys.

[4] Telford, W.M., Geldart, L.P., Sheriff, R.E., (1990). Applied Geophysics Second Edition. Cambridge: Cambridge University Press.

[5] Suhendra Vebrianto (2016). "Eksplorasi Metode Geolistrik: Resistivitas, Polarisasi Terinduksi, dan Potensial Diri". UB Press Malang 
